\title{
Simultaneous morphology evolution and upconversion emission tuning of single Y-based fluoride microcrystal induced by $\mathrm{Sc}^{3+}$ co-doping
}

\author{
E.J. He ${ }^{*}$, S.F. Chen, M.L. Zhang
}

School of Electrical and Electronic Engineering, Anhui Science and Technology University, Fengyang, 233100,

China

\section{ABSTRACT}

Upconversion phosphors composed of both gray-white and gray-black microcrystals were synthesized using a facile hydrothermal route. The microcrystals with different contrast in the SEM images were confirmed to be Y-based and Sc-based microcrystals by SEM, XRD, EDX and elemental mapping. The morphology evolution of Y-based microcrystal induced by $\mathrm{Sc}^{3+}$ co-doping can be ascribed to the variation of anisotropic growth for different crystal planes. We studied the dependence of fluorescence intensity on pump power and investigated the variation of fluorescence decay dynamics for the different compositions. It was found that an increase of the energy transfer rate from $\mathrm{Yb}^{3+}$ to $\mathrm{Er}^{3+}, \mathrm{Ho}^{3+}, \mathrm{Eu}^{3+}$ and $\mathrm{Tm}^{3+}$, and a decrease of the phonon energy by $\mathrm{Sc}^{3+}$ co-doping were responsible for the observed fluorescence tuning. Such a simultaneous morphology evolution and upconversion fluorescence tuning of single Y-based fluoride microcrystal with low phonon energy will show a great potential in microlaser, photovoltaics, and photo-communication.

Keywords: A. Optical materials; A. Inorganic compounds; B. Crystal growth; D. Luminescence; D. Phosphors

\footnotetext{
*Corresponding author. E-mail address: optical_enjiehe@126.com (E. He).
} 


\section{Introduction}

Rare Earth (RE) activated luminescent materials have drawn continued attention in various fields [1-5], due to their unique optical properties arising from their rich energy level structure, narrow excitation/emission bands, long excited state lifetimes, weak background fluorescence, etc [6-11]. Recently, most of the attention is focused on nanocrystals for a variety of potential applications especially as luminescent nano-bioprobes [12-14]. In comparison with doped nanocrystals, RE-doped microcrystals usually show higher luminescence quantum yields due to the smaller surface-to-volume ratio and less surface defects that act as quenching centers. As a result, a rich variety of morphologies and particle sizes can give rise to variations in emission strengths for different emission lines and this is particularly important for RE-doped microcrystals, and their potential application in solar cells, solid state lasers, displays, and optical telecommunication [15-18].

Ion co-doping has been regarded as an efficient strategy for the luminescence tuning and morphology manipulation of RE-doped microcrystals. Recently, remarkable upconversion fluorescence enhancements was accomplished by morphology evolution in $\beta-\mathrm{NaYF}_{4}: \mathrm{Yb}^{3+}, \mathrm{Er}^{3+}$ microcrystals by $\mathrm{K}^{+}$and $\mathrm{Cr}^{3+}$ co-doping $[19,20]$. The influence of $\mathrm{Li}^{+}$co-doping on the upconverison emission of $\beta-\mathrm{NaLuF}_{4}: \mathrm{Yb}^{3+}, \mathrm{Ln}^{3+}(\mathrm{Ln}=\mathrm{Tm}, \mathrm{Ho})$ microcrystals has also been discussed [21]. The luminescence tuning and morphology evolution by non-RE ion co-doping were ascribed to the modification of local crystal field. It is found that co-doping optically active RE ions in microcrystal usually plays a role by acting as a sensitizer for upconversion [22-23]. Obvious upconversion 
emission tuning has been realized in single $\mathrm{LiYF}_{4}: \mathrm{Yb}^{3+}, \mathrm{Ho}^{3+}$ microcrystal by $\mathrm{Ce}^{3+}$ co-doping, but the morphology of microcrystal keeps unchanged, which limits its application [24]. Among various RE-doped microcrystals, $\mathrm{Sc}^{3+}$-codoped microcrystal has been reported rarely [25]. $\mathrm{Sc}^{3+}$ is a fluorophilic ion with the smallest $\mathrm{RE}$ ion radius, and a distinct ionic electron configuration. $\mathrm{Sc}^{3+}$ co-doping can induce some novel spectroscopic properties [26,27]. To the best of our knowledge, simultaneous luminescence tuning and morphology evolution of microcrystalline material induced by $\mathrm{Sc}^{3+}$ co-doping have not been reported to date.

Here we present a facile hydrothermal method to synthesize Y-based fluoride microcrystals co-existing with Sc-based analogs by $\mathrm{Sc}^{3+}$ co-doping at high temperature in hydrothermal synthesis method. By simply tuning the nominal co-doping concentration of $\mathrm{Sc}^{3+}$, we obtained regular Y-based polyhedron microcrystals with different morphologies, and the formation mechanism will be discussed. More impotantly, we also explored the upconversion luminescence tuning of single phace Y-based polyhedron microcrystals and discuss the tuning mechanism. As far as we know, it is the first time report in which variation of the morphology evolution and tuning of the upconversion emission have been realized in single phase Y-based microcrystals by $\mathrm{Sc}^{3+}$ co-doping.

\section{Experimental details}

\subsection{Chemicals}

All of the chemicals were analytical grade and were used as received without any further purification. $\mathrm{NaF}$ (98.0\%) and $\mathrm{HNO}_{3}$ (65.0-68.0\%) were provided by 
Sinopharm Chemical Reagent Co., Ltd. EDTA (ethylenediaminetetraacetic acid, 99.5\%) was purchased from Tianjing Shentong Chemical Reagent Co., Ltd. $\mathrm{Ln}_{2} \mathrm{O}_{3}$ (Ln=Y, Yb, Gd, Sc, Er, Tm, Ho, Eu, Sigma-Aldrich, 99.99\%) were separately dissolved in nitric acid at elevated temperature followed by evaporating the excess $\mathrm{HNO}_{3}$, resulting in the formation of an aqueous solution of the corresponding $\operatorname{Ln}\left(\mathrm{NO}_{3}\right)_{3}$.

\subsection{Preparation}

All the samples were synthesized by a facile hydrothermal method. The corresponding details were presented in Table 1 . In a typical procedure for the synthesis of sample Er4, an aqueous solution containing $\mathrm{Y}\left(\mathrm{NO}_{3}\right)_{3}(0.5 \mathrm{M}, 0.24 \mathrm{~mL})$, $\mathrm{Yb}\left(\mathrm{NO}_{3}\right)_{3}(0.25 \mathrm{M}, 0.16 \mathrm{~mL}), \mathrm{Gd}\left(\mathrm{NO}_{3}\right)_{3}(0.5 \mathrm{M}, 0.08 \mathrm{~mL}), \mathrm{Sc}\left(\mathrm{NO}_{3}\right)_{3}(0.5 \mathrm{M}, 1.56 \mathrm{~mL})$ and $\operatorname{Er}\left(\mathrm{NO}_{3}\right)_{3}(0.5 \mathrm{M}, 0.04 \mathrm{~mL})$ was mixed with deionized water $(30 \mathrm{~mL})$ and EDTA (0.2937 g) under vigorous stirring for $30 \mathrm{~min}$ to form a chelating complex solution. Subsequently, $0.3 \mathrm{~g} \mathrm{NaF}$ was added to the solution to form a colloidal suspension and kept under constant stirring for another 30 min. Finally, the obtained solution was slowly transferred into a $40 \mathrm{~mL}$ Teflon-lined autoclave and kept at $225{ }^{0} \mathrm{C}$ for $48 \mathrm{~h}$. The final products were washed with deionized water and anhydrous ethanol several times, then dried at $90{ }^{0} \mathrm{C}$ for $24 \mathrm{~h}$.

\subsection{Characterization}

X-ray powder diffraction (XRD) measurements were performed on a Rigaku D/Max2550 diffractometer at a scanning rate of $4^{0} \mathrm{~min}^{-1}$, using monochromatic $\mathrm{Cu} \mathrm{K \alpha}$ radiation $(\lambda=0.15406 \mathrm{~nm})$. The morphology and elemental analysis were carried on a 
scanning electron microscope (SEM, Quanta 200, accelerating voltage: $200 \mathrm{kV}$ ) equipped with an energy-dispersive X-ray analysis (EDX, Genesis XM, spot scanning mode), and a JEM-2100F field emission transmission electron microscope (TEM, accelerating voltage: $200 \mathrm{kV}$ ). A Ti sapphire femtosecond laser (Mira-900) was employed as excitation source. A SP 2750i monochromator (ACTON, spectral resolution: $0.008 \mathrm{~nm}$ ) equipped with a PIXIS 100 charge coupled device (CCD, ACTON) was used for spectrum acquisition. Laser confocal microscopy was realized by an OLYMPUS BX51 optical microscope. A 980 nm diode laser (Changchun New Industries Optoelectronics Technology Co., Ltd.) and a boxcar (SRS) were used for upconversion fluorescence decay profile collection. Proper notch filters were placed in front of the monochromator to block the scattering light.

\section{Results and discussion}

\subsection{Crystal structure}

SEM images of sample Er0-4 were shown in Fig. 1. As shown in Fig. 1(a), except for a few thin microrods, the $\mathrm{Sc}^{3+}$-free sample (Er0) was almost entirely composed of short hexagonal prisms with an average size of $7 \mu \mathrm{m}$ in length and $5 \mu \mathrm{m}$ in diameter. Two kinds of morphologies have been observed in the $18 \% \mathrm{Sc}^{3+}$-doped sample (Er1). One is small octadecahedron with cracked ends, and the other is big hexagonal prism with a number of discrete tips (Fig. 1(b)). By doping with higher $\mathrm{Sc}^{3+}$ concentrations (38-78\%, Fig. 1(c)-(e)), the number of irregular octadecahedrons decreased, and the average size of irregular octadecahedrons in sample $\operatorname{Er} 4 \quad\left(78 \% \mathrm{Sc}^{3+}\right)$ was significantly smaller than those included in sample Er2-3. Additionally, a distinct 
amphorous gray-black crystal with increased Sc content was also present in sample Er2-4.

XRD patterns were recorded to investigate the crystal structure of as-prepared samples. As shown in Fig. 2, all the diffraction peaks of $\mathrm{Sc}^{3+}$-free sample can be well indexed with hexagonal $\mathrm{NaYF}_{4}$ (JCPDS 16-0334), which gives evidence for the formation of a single phase crystalline material. When the $\mathrm{Sc}^{3+}$ concentration varies in the range of $18-58 \%$, several additional peaks at $\sim 22^{0}$ and $45^{\circ}$ appear and are ascribed to monoclinic $\mathrm{Na}_{3} \mathrm{ScF}_{6}$ (JCPDS 47-1221), and their intensities keep increasing with the increasing contect of $\mathrm{Sc}^{3+}$. It is suggested that hexagonal $\mathrm{NaYF}_{4}$ and monoclinic $\mathrm{Na}_{3} \mathrm{ScF}_{6}$ coexist in sample Er1-3. Apart from the dominant strong peaks that belong to hexagonal $\mathrm{NaYF}_{4}$, three other weak peaks belonging to monoclinic $\mathrm{Na}_{3} \mathrm{ScF}_{6}$ and two peaks belonging to hexagonal $\mathrm{NaScF}_{4}$ (JCPDS 20-1152) emerged for sample Er4 $\left(78 \% \mathrm{Sc}^{3+}\right)$. We suggest that the microcrystals with a different contrast in SEM (gray-white and gray-black microcrystals, Fig. 1) are Y-based (hexagonal $\mathrm{NaYF}_{4}$ ) and Sc-based (monoclinic $\mathrm{Na}_{3} \mathrm{ScF}_{6}$ and/or hexagonal $\mathrm{NaScF}_{4}$ ) microcrystals, respectively. Additionally, the peaks around $22^{0}$ and $45^{\circ}$ that belong to monoclinic $\mathrm{Na}_{3} \mathrm{ScF}_{6}$ disappeared in sample Er4, which can be ascribed to the higher $\mathrm{Sc}^{3+}$ concentration of precursor solution (78\%). The symmetry of hexagonal $\mathrm{NaScF}_{4}$ is higher than that for monoclinic $\mathrm{Na}_{3} \mathrm{ScF}_{6}$, and needs the higher binding energy. The higher $\mathrm{Sc}^{3+}$ concentration means the smaller interionic distance, and it's beneficial to provide a high binding energy.

To verify the identification and to determine the elemental composition of the two 
kinds of microcrystals, EDX spectra were collected in the spot scanning mode. The scanning spots labeled as red and blue solid circles in the insets of Fig. 3 correspond to Y- and Sc-based microcrystals suggested above, respectively. The EDX spectra confirmed the presence of Na, F, Y, Yb, Gd, Er elements in all the samples, and additional Sc in $\mathrm{Sc}^{3+}$-doped samples. Furthermore, the Sc content in blue region was much higher than that in red region (Fig. 3(b) and (c)), which agrees well with the XRD and SEM results. Although the amount of $\mathrm{Sc}^{3+}$ that really entered into the Y- or Sc-based crystal lattices increased with the increasing of the added $\mathrm{Sc}^{3+}$, the actual amount, especially for the Y-based microcrystals, was clearly smaller than the nominal concentration, which can be ascribed to the large difference in ionic radius between $\mathrm{Sc}^{3+}$ and other RE ions. As shown in Fig. 2, the diffraction peaks associated with the hexagonal $\mathrm{NaYF}_{4}$ phase shift slightly to the larger angle when the actual $\mathrm{Sc}^{3+}$ content increases. Combing with Bragg's Law, we can find it was caused by the decrease of crystalline interplanar spacing, which was induced by the introduction of a small amount of $\mathrm{Sc}^{3+}$ (with the smallest $\mathrm{RE}$ ionic radius) into the lattices.

As shown in Fig. 4, F, Na, Sc, Y, Gd, Yb and Er elements appear in sample Er4, simultaneously. Figs. 4(b) and (c) show clearly that F and Na elements distribute homogeneously in the Y- and Sc-based microcrystals. More importantly, the Sc element mainly distributes in the Sc-based microcrystals (Fig. 4(d)), and the Y, Gd, Yb and Er elements mainly distributed in the Y-based microcrystals (Fig. 4(e)-(h)). It agrees well with the XRD and EDX results which also suggest the formation of two types of microcrystals with different composition and crystal structure. 


\subsection{Morphology evolution}

To understand the morphology evolution mechanism of Y-based microcrystals, the influence of hydrothermal synthesis temperature and time were studied and used to obtain insight in the intermediate products. The SEM pictures of obtained intermediate samples corresponding to sample Er0-4 are shown in Figs. 5 and 6, respectively. It can be clearly seen that the $\mathrm{Sc}^{3+}$-free sample (Er01) was composed of a large number of nanocrystals (around 200 nm, Fig. 5(a)). Before the hydrothermal action, the complexation between RE ions and EDTA molecules was strong. The obtained intermediate nanocrystals (sample Er01) for low reaction temperature and short reation times can be well indexed with the metastable cubic $\mathrm{Na}_{5} \mathrm{Y}_{9} \mathrm{~F}_{32}$ structure (JCPDS No. 27-1428, not shown). It has been reported that the radius of doped ion plays a vital role for the crystal stability of $\mathrm{NaYF}_{4}$, in which the smaller radius ions favor formation of the cubic phase while the bigger ions are inclined to form the hexagonal phase $[28,29]$. On the other hand, the number of Y-based microcrystals increased gradually with the increasing of the doped $\mathrm{Sc}^{3+}$ (Fig. 5(b)-(e)), and the number of nanocrystals attached on their surfaces decreased simultaneously. When the nominal concentration of $\mathrm{Sc}^{3+}$ reaches $78 \%$, a complete phase transformation of Y-based microcrystals from cubic to hexagonal has been realized (Fig. 5(e)). It indicates that the small radius $\mathrm{Sc}^{3+}$ favored the formation of hexagonal $\mathrm{NaYF}_{4}$. Meanwhile, the growth of the six crystal planes belonging to the $\{10 \overline{1} 0\}$ family and the two belonging to the $\{0001\}$ family have been restrained, and those for the 12 crystal planes of $\{20 \overline{2} 1\}$ family have been accelerated (Fig. 5(b)-(e)). A part of 
microcrystals with a morphology of dodecahedron has also been found (Fig. 5(e)), which was induced by the oriented growth of Y-based microcrystal. When the reaction time decreased to $2 \mathrm{~h}$, only a few microcrystals with a size of $1-2 \mu \mathrm{m}$ were found in the samples doped 38\%, 58\% and 78\% $\mathrm{Sc}^{3+}$ (Fig. 6).

All the results discussed above confirm that the introduction of $\mathrm{Sc}^{3+}$ causes a faster growth of Y-based microcrystal. It induced the accelerated growth of $\{20 \overline{2} 1\}$ crystal planes, and the decelerated growth of $\{10 \overline{1} 0\}$ and $\{0001\}$ crystal planes, respectively. The observed morphology evolution of octahedron $\rightarrow$ icosahedron $\rightarrow$ octadecahedron (Fig. 5(c)-(e)) can be ascribed to the anisotropic growth of different crystal planes. It should be noted that the actual number of $\mathrm{Sc}^{3+}$ ions that entered into the crystal lattices of Y-based microcrystals was very low. A large part of $\mathrm{Sc}^{3+}$ was used to form monoclinic/hexagonal Sc-based microcrystals under hydrothermal atmosphere at high temperature and long reaction time. As the radius of non- $\mathrm{Sc}^{3+} \mathrm{RE}$ ion $\left(\mathrm{Y}^{3+}, \mathrm{Gd}^{3+}, \mathrm{Er}^{3+}\right.$ and $\mathrm{Yb}^{3+}$ ) is much bigger than that of $\mathrm{Sc}^{3+}$, these ions are not easily incorporated into the Sc-based microcrystals (Fig. 4). The rest of Sc ${ }^{3+}$ probably served as the separant of the Y-based crystal seeds, and helped them to grow to the critical size for the transformation of cubic to hexagonal.

\subsection{Upconversion emission tuning}

Normalized upconversion emission spectra and photographs of single luminescent Y-based microcrystal are presented in Fig. 7. The corresponding upconversion mechanisms are shown in Fig. 8. A series of typical upconversion emission intensity vs pump power plots for sample Er0-4 is also presented in Fig. 9. All the obtained 
slopes were close to 2, which is consistent with the suggested upconversion mechanisms in suggested in Fig. 8. In the $\mathrm{Er}^{3+}, \mathrm{Ho}^{3+}$ and $\mathrm{Eu}^{3+}$ doped samples, the relative intensity of green emission band (Fig. 8(a)-(c): ${ }^{2} \mathrm{H}_{11 / 2} /{ }^{4} \mathrm{~S}_{3 / 2} \rightarrow{ }^{4} \mathrm{I}_{15 / 2}\left(\mathrm{Er}^{3+}\right)$, $\left.{ }^{5} \mathrm{~F}_{4} /{ }^{5} \mathrm{~S}_{2} \rightarrow{ }^{5} \mathrm{I}_{8}\left(\mathrm{Ho}^{3+}\right),{ }^{5} \mathrm{D}_{1} \rightarrow{ }^{7} \mathrm{~F}_{1,2}\left(\mathrm{Eu}^{3+}\right)\right)$ to the red counterpart (Fig. 8(a)-(c): ${ }^{4} \mathrm{~F}_{9 / 2} \rightarrow{ }^{4} \mathrm{I}_{15 / 2}$ $\left.\left(\mathrm{Er}^{3+}\right),{ }^{5} \mathrm{~F}_{5} \rightarrow{ }^{5} \mathrm{I}_{8}\left(\mathrm{Ho}^{3+}\right),{ }^{5} \mathrm{D}_{0} \rightarrow{ }^{7} \mathrm{~F}_{3}\left(\mathrm{Eu}^{3+}\right)\right)$ increased with the increasing of co-doping of $\mathrm{Sc}^{3+}$ (Fig. 7(a)-(c)). On the contrary, for $\mathrm{Tm}^{3+}$ the intensity ratio of blue emission band $\left({ }^{1} \mathrm{D}_{2} \rightarrow{ }^{3} \mathrm{~F}_{4}\right)$ to the near-infrared emission band $\left({ }^{3} \mathrm{H}_{4} \rightarrow{ }^{3} \mathrm{H}_{6}\right)$ decreased with an increase of $\mathrm{Sc}^{3+}$ of co-doping in the $\mathrm{Tm}^{3+}$ doped sample (Fig. 7(d)). Obvious upconversion fluorescence enhancement has been realized in $\mathrm{Yb}^{3+}, \mathrm{Er}^{3+}$ and $\mathrm{Sc}^{3+}$ triply-doped $\mathrm{NaYF}_{4}$ microcrystal, which was ascribed to the decrease of local symmetry proposed by Huang et al [25]. In the current system, the fluorescence intensity ratio of the forced electric dipole transition of ${ }^{5} \mathrm{D}_{0} \rightarrow{ }^{7} \mathrm{~F}_{2}$ to the magnetic dipole transition of ${ }^{5} \mathrm{D}_{0} \rightarrow{ }^{7} \mathrm{~F}_{1}$ shows no significant change in each of $\mathrm{Eu}^{3+}$ containing samples (the inset of Fig. 7(c)), which indicates that the local symmetry around luminescent ion has not changed significantly by $\mathrm{Sc}^{3+}$ co-doping. We can argue that the upconversion emission tuning was probably not induced by the variation of local symmetry.

However, the line shapes of some emission bands (such as ${ }^{4} \mathrm{~F}_{9 / 2} \rightarrow{ }^{4} \mathrm{I}_{15 / 2}$ of $\mathrm{Er}^{3+}$, ${ }^{5} \mathrm{D}_{0} \rightarrow{ }^{7} \mathrm{~F}_{3}$ of $\mathrm{Eu}^{3+}$, and ${ }^{3} \mathrm{H}_{4} \rightarrow{ }^{3} \mathrm{H}_{6}$ of $\mathrm{Tm}^{3+}$ ) change obviously with $\mathrm{Sc}^{3+}$ content, (Fig. 7). As the $4 f$ electrons of trivalent RE ions are shielded by the outer $5 s^{2} 5 p^{6}$ electrons, the electron-phonon coupling is very weak, and its influence on the line shape can be ignored. The RE ion energy level of ${ }^{2 \mathrm{~S}+1} \mathrm{~L}_{\mathrm{J}}(\mathrm{S}, \mathrm{L}$, and $\mathrm{J}$ are spin, angular, and total quantum numbers, respectively) has a degeneracy of $2 \mathrm{~J}+1$, and can be splitted into at 
most $2 \mathrm{~J}+1$ Stark energy levels by crystal filed. The sub-emission peaks associated with a same emission band in Fig. 7 can be ascribed to the transitions from different Stark energy levels of excited state to the ground state counterparts. For the emission bands mentioned above, the peak positions of these sub-transitions keeps unchanged for different $\mathrm{Sc}^{3+}$-doped samples, but the relative emission intensities change obviously. As the energy gap between ${ }^{2} \mathrm{H}_{11 / 2}$ and ${ }^{4} \mathrm{~S}_{3 / 2}$ of $\mathrm{Er}^{3+}$ is very small, the emission intensity ratio of ${ }^{2} \mathrm{H}_{11 / 2} \rightarrow{ }^{4} \mathrm{I}_{15 / 2}$ to ${ }^{4} \mathrm{~S}_{3 / 2} \rightarrow{ }^{4} \mathrm{I}_{15 / 2}$ can be employed to measure the local temperatures around luminescent centers [30,31], and the higher ratio means the higher local temperature. We calculate the ratio for different samples, and find the ratio varies obviously with the variation of $\mathrm{Sc}^{3+}$-doped concentration, which means the local temperatures changed obviously. It induces different populations for the Stark energy levels that belong to a same excited/ground state, thus giving different sub-transition intensities for different $\mathrm{Sc}^{3+}$-doped samples.

From the EDX measurements (Fig. 3), we can conclude that the most of RE ions were incorporated in the Y-based microcrystals, except for $\mathrm{Sc}^{3+}$. From sample Er0 to Er4, the actual $\mathrm{Er}^{3+}$ concentrations of the Y-based microcrystals were 1.41\%, 1.43\%, 1.39\%, $1.37 \%$ and $1.43 \%$, respectively. All the relative errors were less than $3 \%$. For the actual $\mathrm{Yb}^{3+}$ concentration, the same result has been obtained, apart from a maximum relative error of $2.8 \%$. Additionally, we have also found the upconversion emission intensity of Sc-based microcrystals was much weaker than that in Y-based counterpart. All these suggest that the upconversion emission tuning was probably not caused by the variations of the activator or sensitizer ion concentrations, and their 
ratio.

The diameter of laser beam used in current system can only be focused to $1 \mu \mathrm{m}$, which is much smaller than the average size of Y-based microcrystal. We focused the excitation light spot on the different positions of single microcrystal, and no significant variation of relative intensity was found. It indicates that the upconversion emission tuning was not caused by a variation in the position of the excitation beam. For single Y-based microcrystals with different morphologies, the relative intensity of different emission bands stays nearly unchanged, which shows that the influence of morphology on the fluorescence tuning can also be ignored.

The observed upconversion emission tuning in Fig. 7(a)-(c) indicates that the relative population between the emitting energy levels for green and red emission has been changed strongly by $\mathrm{Sc}^{3+}$ co-doping. As shown in Fig. 8(c), the upconversion emission of $\mathrm{Eu}^{3+}$ is realized by a cooperative energy transfer process that involves two excited $\mathrm{Yb}^{3+}$ ions [32]. It suggests that the employed excitation power was high enough to bridge the initial state $\left({ }^{2} \mathrm{~F}_{7 / 2}\right)$ and the emission states $\left({ }^{5} \mathrm{D}_{0,1}\right)$. The distance $R$ between luminescent ion $\left(\mathrm{Er}^{3+}, \mathrm{Ho}^{3+}\right.$ and $\left.\mathrm{Eu}^{3+}\right)$ and sensitizer ion $\left(\mathrm{Yb}^{3+}\right)$ will be shortened after the $\mathrm{Sc}^{3+}$ (the smallest radius RE ion) enters into the crystal lattice. The energy transfer from the sensitizer ion to the luminescent ion involves dipole-dipole interaction, in which case the transfer rate is proportional to $R^{-6}[33,34]$. In the current system, the higher transfer rate can be induced by $\mathrm{Sc}^{3+}$ co-doping. As the excitation power is sufficiently high, the higher energy level of green fluorescence (Fig. 8(a)-(c): $\left.{ }^{2} \mathrm{H}_{11 / 2} /{ }^{4} \mathrm{~S}_{3 / 2}\left(\mathrm{Er}^{3+}\right),{ }^{5} \mathrm{~F}_{4} /{ }^{5} \mathrm{~S}_{2}\left(\mathrm{Ho}^{3+}\right),{ }^{5} \mathrm{D}_{1}\left(\mathrm{Eu}^{3+}\right)\right)$ can be populated much easier than that 
for the red counterpart.

On the other hand, as the maximum phonon energy of $\mathrm{NaLnF}_{4}$ ( $\mathrm{Ln}=\mathrm{RE}$ element) decreased gradually by reducing the atomic weight of RE element [35], the maximum phonon energy will be reduced by $\mathrm{Sc}^{3+}$ codoping as $\mathrm{Sc}$ is the lightest $\mathrm{RE}$ element, and the fact that $\mathrm{Sc}^{3+}$ radius is the smallest among trivalent $\mathrm{RE}$ ions. The multi-phonon relaxation rate for various processes (Fig. 8(a)-(c): ${ }^{4} \mathrm{~S}_{3 / 2} \rightarrow{ }^{4} \mathrm{~F}_{9 / 2},{ }^{4} \mathrm{I}_{11 / 2} \rightarrow{ }^{4} \mathrm{I}_{13 / 2}\left(\mathrm{Er}^{3+}\right)$; $\left.{ }^{5} \mathrm{~S}_{2} /{ }^{5} \mathrm{~F}_{4} \rightarrow{ }^{5} \mathrm{~F}_{5},{ }^{5} \mathrm{I}_{6} \rightarrow{ }^{5} \mathrm{I}_{7}\left(\mathrm{Ho}^{3+}\right) ;{ }^{5} \mathrm{D}_{1} \rightarrow{ }^{5} \mathrm{D}_{0}\left(\mathrm{Eu}^{3+}\right)\right)$ will be decreased by reducing the phonon energy, which reduces the relative population for the emitted energy level of red fluorescence (Fig. 8(a)-(c)) and increases the relative population of the green counterpart, simultaneously. For $\mathrm{Tm}^{3+}$-contained Y-based microcrystal, the reduction of the maximum phonon energy can render the population of ${ }^{1} \mathrm{D}_{2}$ state more difficult than ${ }^{3} \mathrm{H}_{4}$ state as a three-photon process and a cross relaxation process $\left(\left({ }^{1} \mathrm{G}_{4},{ }^{3} \mathrm{H}_{4}\right) \rightarrow\right.$ $\left({ }^{1} \mathrm{D} 2,{ }^{3} \mathrm{~F}_{4}\right)$ ) have been involved in the ${ }^{1} \mathrm{D}_{2} \rightarrow{ }^{3} \mathrm{~F}_{4}$ transition (Fig. $7(\mathrm{~d})$ ), which induced the relative intensity tuning as shown in Fig. 7(d).

Typical normalized upconversion fluorescence decay profiles of sample Er0-4 (for ${ }^{4} \mathrm{~S}_{3 / 2} \rightarrow{ }^{4} \mathrm{I}_{15 / 2}$ and ${ }^{4} \mathrm{~F}_{9 / 2} \rightarrow 4 \mathrm{I}_{15 / 2}$ transitions) are presented in Fig. 10. By fitting these decay curves with bio-exponential functions, the rise and decay times were extracted, as shown in Table 2, in which the ratio denotes the ratio of rise or decay time for sample Er0 to that for sample Eri $(i=0,1, \ldots, 4)$. It can be seen clearly that the rise time decreased gradually with increasing of $\mathrm{Sc}^{3+}$ concentration for both transitions. Furthermore, it decreased slower for the ${ }^{4} \mathrm{~F}_{9 / 2} \rightarrow 4 \mathrm{I}_{15 / 2}$ transition than for the ${ }^{4} S_{3 / 2} \rightarrow{ }^{4} \mathrm{I}_{15 / 2}$ transition, which was induced by the stiffer competition between the 
increase of the energy transfer rate and the decrease of the multi-phonon relaxation rate, as there are two multi-phonon relaxation processes have been involved the ${ }^{4} \mathrm{~F}_{9 / 2} \rightarrow 4 \mathrm{I}_{15 / 2}$ transition and only one for ${ }^{4} \mathrm{~S}_{3 / 2} \rightarrow{ }^{4} \mathrm{I}_{15 / 2}$ transition (Fig. 8). Simultaneously, we have found the decay time increased gradually with increasing of $\mathrm{Sc}^{3+}$ concentration for both transitions, and the rate of increase is faster for the red transition than that for the green transition, which gives a clear evidence of the increase of maximum phonon energy. For the ${ }^{4} \mathrm{~S}_{3 / 2} \rightarrow{ }^{4} \mathrm{I}_{15 / 2}$ emission band, we have also found that the obtained slope by linear fitting increased gradually with the increasing of $\mathrm{Sc}^{3+}$ concentration, as opposed to the ${ }^{4} \mathrm{~F}_{9 / 2} \rightarrow 4 \mathrm{I}_{15 / 2}$ emission band (Fig. 9), which proves the previous discusssion about the adjustion of relative populations by decreasing the maximum phonon energy to be reasonable.

Additionally, with a tripling in the $\mathrm{Yb}^{3+}$ doped concentration of sample Er0-4 (Table 1), the similar morphology evolution has also been observed in Fig. 11. More significantly, the upconversion emission tuning turns to be more distinct and can be discerned by naked eye (Fig. 12), which provides further powerful evidence for the increase of the energy transfer rate by $\mathrm{Sc}^{3+}$ codoping. As a result, the increase of energy transfer rate to different degrees for these main upconversion trnasitions, and the decrease of maximum phonon energy by $\mathrm{Sc}^{3+}$ codoping should be mainly responsible for the observed upconversion emission tuning.

More recently, simultaneous quasi-onedimensional propagation and tuning of upconversion luminescence in a single $\beta-\mathrm{NaYF}_{4}: \mathrm{Yb}^{3+}, \mathrm{Er}^{3+}$ microtube has been realized by Gao et al [36], which indicates the upconversion emission in microcrystal 
with regular morphology could be confined to a micro-scale. Analogously, if the upconversion emission is confined to the current octadecahedron microcrystal, it can be acted as a micro laser resonator, which can eliminate excitation energy losses by the two sharp tips of octadecahedron.

\section{Conclusion}

In conclusion, with $\mathrm{Sc}^{3+}$ co-doping, a simultaneous morphology evolution and the upconversion emission tuning in single microcrystallites has been realized by a facile hydrothermal synthesis strategy. Regular Y-based microcrystals with various polyhedron morphologies accompanied with Sc-based counterpart of a different morphology can be synthesized and controlled via the $\mathrm{Sc}^{3+}$ concentration. Based on the crystal phases identified and morphology evolution observed, a mechanism for the formation of the Y-based microcrystal has been presented. Upconversion emission tuning of main emission bands for single Y-based microcrystal which contained luminescent ions $\left(\mathrm{Er}^{3+}, \mathrm{Ho}^{3+}, \mathrm{Eu}^{3+}, \mathrm{Tm}^{3+}\right)$ has been significantly improved by $\mathrm{Sc}^{3+}$ co-doping. The spectroscopic results indicated that the change of relative population for various emitting excited states is induced by the variation of the energy transfer rate, and that the maximum phonon energy were the main reasons for the observed upconversion emission tuning. The current study provides a simple and new strategy for simultaneous morphology evolution and upconversion emission tuning of single RE-doped microcrystals, which be important for the development of new luminescent materials in the fields of microlaser, photovoltaics, and photo-communication. 


\section{Acknowledgements}

This work was financially supported by the Excellent Youth Talents Support Plan in Universities of Anhui Province (2014), the Development Object of Young and Middle-aged Discipline Leaders in AHSTU (2015), the Outstanding Young and Middle-aged Backbone Teachers of AHSTU (2013), the Information and Communication Engineering Key Discipline of AHSTU (AKZDXK2015C02), and the National Science Foundation of China (51472005). We would like to show our sincerest appreciations for the contributions to the paper from Prof. Andries Meijerink (Utrecht University) and Prof. Martin Moskovits (University of California, Santa Barbara).

\section{References}

[1] H.H. Gorris, O.S. Wolfbeis, Angew. Chem. Int. Ed. 52 (2013) 3584-3600.

[2] M. Xin, D.T. Tu, H.M. Zhu, W.Q. Luo, Z.G. Liu, P. Huang, R.F. Li, Y.G. Cao, X.Y. Chen, J. Mater. Chem. C 3 (2015) 7286-7293.

[3] S.W. Hao, L.M. Yang, H.L. Qiu, R.W. Fan, C.H. Yang, G.Y. Chen, Nanoscale 7 (2015) 10775-10780.

[4] R. Cheng, Y.R. Chen, Z.Q. Li, X.H. Chen, P.X. Yang, H.B. Zhu, Y.L. Huang, Z. Sun, S.M. Huang, J. Mater. Sci-Mater. El. 25 (2014) 4066-4073.

[5] X.H. He, B. Yan, CrystEngComm, 17 (2015) 621-627.

[6] B.R. Judd, Phys. Rev. 127 (1962) 750-761.

[7] G.S. Ofelt, J. Chem. Phys. 37 (1962) 511-520.

[8] X.Y. Huang, Q.Y. Zhang, J. Appl. Phys. 107 (2010) 063505. 
[9] S. Sarkar, B. Meesaragandla, C. Hazra,V. Mahalingam, Adv. Mater. 25 (2013) 856-860.

[10] R. Kolesov, K. Xia, R. Reuter, R. Stöhr, A. Zappe, J. Meijer, P.R. Hemmer, J. Wrachtrup, Nat. Commun. 3 (2012) 1029.

[11] W. Zheng, P. Huang, D.T. Tu, E. Ma, H.M. Zhu, X. Y. Chen, Chem. Soc. Rev. 44 (2015) 1379-1415.

[12] S. Lu, D.T. Tu, P. Hu, J. Xu, R.F. Li, M. Wang, Z. Chen, X.Y. Chen, Angew. Chem. Int. Ed. 54 (2015) 7915-7919.

[13] S. Majeed, M. Bashir, S.A. Shivashankar, J. Nanopart. Res. 17 (2015) 309.

[14] T.S. Yang, Y. Sun, Q. Liu, W. Feng, P.Y. Yang, F.Y. Li, Biomaterials, 33 (2012) 3733-3742.

[15] G.E. Arnaoutakis, J. Marques-Huesoa, A. Ivaturi, S. Fischer, J.C. Goldschmidt, K.W. Krämer, B.S. Richards, Sol. Energ. Mat. Sol. C. 140 (2015) 217-223.

[16] F. Wang, X.G. Liu, Chem. Soc. Rev. 38 (2009) 976-989.

[17] E. Downing, L. Hesselink, J. Ralston, R. Macfarlane, Science 273 (1996) 1185-1189.

[18] G. Rumbles, Nature, 409 (2001) 572-573.

[19] M.Y. Ding, D.Q. Chen, S.L. Yin, Z.G. Ji, J.S. Zhong, Y.R. Ni, C.H. Lu, Z.Z. Xu, Sci. Rep-UK 5 (2015) 12745.

[20] C.Y. Wang, X.H. Cheng, J. Alloy. Compd. 649 (2015) 196-203.

[21] H. Lin, D.K. Xu, D.D. Teng, S.H. Yang, Y.L. Zhang, New J. Chem. 39 (2015) 2565-2572. 
[22] L.L. Wang, M. Lan, Z.Y. Liu, G.S. Qin, C.F. Wu, X. Wang, W.P. Qin, W. Huang, L. Huang, J. Mater. Chem. C 1 (2013) 2485-2490.

[23] G.F. Wang, W.P. Qin, L.L. Wang, G.D. Wei, P.F. Zhu, R. Kim, Opt. Express 16 (2008) 11907-11914.

[24] W. Gao, R.B. Wang, Q.Y. Han, J. Dong, L.X. Yan, H.R. Zheng, J. Phys. Chem. C 119 (2015) 2349-2355.

[25] Q.M. Huang, J.C. Yu, En Ma, K.M. Lin, J. Phys. Chem. C 114 (2010) 4719-4724.

[26] X.H. He, B. Yan, Cryst. Growth Des. 14 (2014) 3257-3263.

[27] X. Teng, Y.H. Zhu, W. Wei, S.C. Wang, J.F. Huang, R. Naccache, W.B. Hu, A.I.Y. Tok, Y. Han, Q.C. Zhang, Q.L. Fan, W. Huang, J.A. Capobianco, L. Huang, J. Am. Chem. Soc. 134 (2012) 8340-8343.

[28] Q.Q. Dou, Y. Zhang, Langmuir 27 (2011) 13236-13241.

[29] D.L. Gao, X.Z. Zhang, W. Gao, ACS Appl. Mater. Interfaces 5 (2013) 9732-9739.

[30] L. Aigouy, G. Tessier, M. Mortier, B. Charlot, Appl. Phys. Lett. 87 (2005) 184105.

[31] F. Auzel, Chem. Rev. 104 (2004) 139-174.

[32] Y. Dwivedi, S.N. Thakur, S.B. Rai, Appl. Phys. B 89 (2007) 45-51.

[33] A. Chalzel, J. Chem. Phys. 67 (1977) 4735.

[34] S. Saini, H. Singh, B. Bangchi, J. Chem. Sci. 118 (2006) 23-35.

[35] M.M. Lage, R.L. Moreira, F.M. Matinaga, J.Y. Gesland, Chem. Mater. 17 (2005) 
4523-4529.

[36] D.L. Gao, D.P. Tian, X.Y. Zhang, W. Gao, Sci. Rep. 6 (2016) 22433. 
Table 1 Details of as-prepared samples.

\begin{tabular}{|c|c|c|c|c|c|c|c|c|c|c|}
\hline \multirow{2}{*}{ Name } & \multicolumn{8}{|c|}{ Nominal molar content of RE ion (\%) } & \multicolumn{2}{|c|}{ Hydrothermal condition } \\
\hline & $\mathrm{Sc}^{3+}$ & $\mathrm{Yb}^{3+}$ & $\mathrm{Y}^{3+}$ & $\mathrm{Gd}^{3+}$ & $\mathrm{Er}^{3+}$ & $\mathrm{Ho}^{3+}$ & $\mathrm{Eu}^{3+}$ & $\mathrm{Tm}^{3+}$ & Temperature $\left({ }^{0} \mathrm{C}\right)$ & Time (h) \\
\hline Er0 & 0 & 19.6 & 58.8 & 19.6 & 2 & 0 & 0 & 0 & & \\
\hline Er1 & 18 & 16 & 48 & 16 & 2 & 0 & 0 & 0 & & \\
\hline Er2 & 38 & 12 & 36 & 12 & 2 & 0 & 0 & 0 & 225 & 48 \\
\hline Er3 & 58 & 8 & 24 & 8 & 2 & 0 & 0 & 0 & & \\
\hline Er4 & 78 & 4 & 12 & 4 & 2 & 0 & 0 & 0 & & \\
\hline Er5 & 0 & 58.8 & 19.6 & 19.6 & 2 & 0 & 0 & 0 & & \\
\hline Er6 & 18 & 48 & 16 & 16 & 2 & 0 & 0 & 0 & & \\
\hline Er7 & 38 & 36 & 12 & 12 & 2 & 0 & 0 & 0 & 225 & 48 \\
\hline Er8 & 58 & 24 & 8 & 8 & 2 & 0 & 0 & 0 & & \\
\hline Er9 & 78 & 12 & 4 & 4 & 2 & 0 & 0 & 0 & & \\
\hline Er01 & 0 & 19.6 & 58.8 & 19.6 & 2 & 0 & 0 & 0 & & \\
\hline Er11 & 18 & 16 & 48 & 16 & 2 & 0 & 0 & 0 & & \\
\hline Er21 & 38 & 12 & 36 & 12 & 2 & 0 & 0 & 0 & 180 & 12 \\
\hline Er31 & 58 & 8 & 24 & 8 & 2 & 0 & 0 & 0 & & \\
\hline Er41 & 78 & 4 & 12 & 4 & 2 & 0 & 0 & 0 & & \\
\hline Er02 & 0 & 19.6 & 58.8 & 19.6 & 2 & 0 & 0 & 0 & & \\
\hline Er12 & 18 & 16 & 48 & 16 & 2 & 0 & 0 & 0 & & \\
\hline Er22 & 38 & 12 & 36 & 12 & 2 & 0 & 0 & 0 & 180 & 2 \\
\hline Er32 & 58 & 8 & 24 & 8 & 2 & 0 & 0 & 0 & & \\
\hline Er42 & 78 & 4 & 12 & 4 & 2 & 0 & 0 & 0 & & \\
\hline Ho0 & 0 & 19.6 & 58.8 & 19.6 & 0 & 2 & 0 & 0 & & \\
\hline Ho1 & 18 & 16 & 48 & 16 & 0 & 2 & 0 & 0 & & \\
\hline Ho2 & 38 & 12 & 36 & 12 & 0 & 2 & 0 & 0 & 225 & 48 \\
\hline Ho3 & 58 & 8 & 24 & 8 & 0 & 2 & 0 & 0 & & \\
\hline Ho4 & 78 & 4 & 12 & 4 & 0 & 2 & 0 & 0 & & \\
\hline Eu0 & 0 & 19.6 & 58.8 & 19.6 & 0 & 0 & 2 & 0 & & \\
\hline Eu1 & 18 & 16 & 48 & 16 & 0 & 0 & 2 & 0 & & \\
\hline Eu2 & 38 & 12 & 36 & 12 & 0 & 0 & 2 & 0 & 225 & 48 \\
\hline Eu3 & 58 & 8 & 24 & 8 & 0 & 0 & 2 & 0 & & \\
\hline Eu4 & 78 & 4 & 12 & 4 & 0 & 0 & 2 & 0 & & \\
\hline $\mathrm{Tm} 0$ & 0 & 19.6 & 58.8 & 19.6 & 0 & 0 & 0 & 2 & & \\
\hline Tm1 & 18 & 16 & 48 & 16 & 0 & 0 & 0 & 2 & & \\
\hline $\operatorname{Tm} 2$ & 38 & 12 & 36 & 12 & 0 & 0 & 0 & 2 & 225 & 48 \\
\hline $\operatorname{Tm} 3$ & 58 & 8 & 24 & 8 & 0 & 0 & 0 & 2 & & \\
\hline $\mathrm{Tm} 4$ & 78 & 4 & 12 & 4 & 0 & 0 & 0 & 2 & & \\
\hline
\end{tabular}


Table 2 Rise and decay times of sample Er0-4 for the transitions ${ }^{4} \mathrm{~S}_{3 / 2} \rightarrow{ }^{4} \mathrm{I}_{15 / 2}$ (monitored wavelength: $538.34 \mathrm{~nm}$ ) and ${ }^{4} \mathrm{~F}_{9 / 2} \rightarrow 4 \mathrm{I}_{15 / 2}$ (monitored wavelength: 653.11 nm) obtained by fitting with bio-exponential functions (ratio denotes the ratio of rise or decay time for sample Er0 to that for sample Eri $(i=0,1, \ldots, 4))$.

\begin{tabular}{ccccccccc}
\hline & \multicolumn{3}{c}{${ }^{4} \mathrm{~S}_{3 / 2} \rightarrow{ }^{4} \mathrm{I}_{15 / 2}(538.34 \mathrm{~nm})$} & \multicolumn{4}{c}{${ }^{4} \mathrm{~F}_{9 / 2} \rightarrow{ }^{4} \mathrm{I}_{15 / 2}(653.11 \mathrm{~nm})$} \\
\cline { 2 - 8 } & Rise $(\mu \mathrm{s})$ & Ratio & Decay $(\mu \mathrm{s})$ & Ratio & Rise $(\mu \mathrm{s})$ & Ratio & Decay $(\mu \mathrm{s})$ & Ratio \\
\hline Er0 & 66.44 & 1.00 & 100.18 & 1.00 & 34.50 & 1.00 & 160.99 & 1.00 \\
Er1 & 50.82 & 0.76 & 111.01 & 1.11 & 29.43 & 0.85 & 169.19 & 1.05 \\
Er2 & 44.91 & 0.68 & 123.47 & 1.23 & 25.58 & 0.74 & 177.34 & 1.10 \\
Er3 & 35.96 & 0.54 & 135.66 & 1.35 & 20.88 & 0.61 & 182.38 & 1.13 \\
Er4 & 21.75 & 0.33 & 145.62 & 1.45 & 19.52 & 0.57 & 188.70 & 1.17 \\
\hline
\end{tabular}

\section{Figure captions}

Fig. 1. SEM images of sample (a) Er0, (b) Er1, (c) Er2, (d) Er3 and (e) Er4 (scaling factor: $30 \mu \mathrm{m})$.

Fig. 2. XRD patterns of sample Er0-4.

Fig. 3. EDX spectra of sample (a) Er0, (b) Er2 and (c) Er4 (inset: the SEM image for the corresponding sample, red and blue spots indicate the locations of scanning spots).

Fig. 4. (a) SEM picture of sample Er4 and corresponding element mappings for (b) F, (c) Na, (d) Sc, (e) Y, (f) Gd, (g) Yb and (h) Er elements (Collect condition: Res, 512x400; Dwell, $200 \mu$ s; ROIs, 2; Frames, 64).

Fig. 5. SEM pictures of sample (a) Er01, (b) Er11, (c) Er21, (d) Er31 and (e) Er41 (scaling factor: $20 \mu \mathrm{m}$ ), and the TEM pictures of small nanocrystals for the corresponding samples (the scaling factor of inset: $200 \mathrm{~nm}$ ). 
Fig. 6. SEM pictures of sample (a) Er02, (b) Er12, (c) Er22, (d) Er32 and (e) Er42 (scaling factor: $20 \mu \mathrm{m}$ ).

Fig. 7. Upconversion emission spectra of single Y-based microcrystal for (a) $\mathrm{Er}^{3+}$ (normalized to ${ }^{4} \mathrm{~F}_{9 / 2} \rightarrow{ }^{4} \mathrm{I}_{15 / 2}$ ), (b) $\mathrm{Ho}^{3+}$ (normalized to ${ }^{5} \mathrm{~F}_{5} \rightarrow{ }^{5} \mathrm{I}_{8}$, except for sample Ho4), (c) $\mathrm{Eu}^{3+}$ (normalized to ${ }^{5} \mathrm{D}_{0} \rightarrow{ }^{7} \mathrm{~F}_{3}$, inset: the amplification of $585-625 \mathrm{~nm}$ spectral region) and (d) $\mathrm{Tm}^{3+}$ (normalized to ${ }^{3} \mathrm{H}_{4} \rightarrow{ }^{3} \mathrm{H}_{6}$ ) contained samples ( $\lambda_{\text {exc }}=980 \mathrm{~nm}$, inset: luminescent photographs for single microcrystal).

Fig. 8. Schematic energy level diagrams with proposed upconversion mechanisms for $\mathrm{Yb}^{3+}$ and (a) $\mathrm{Er}^{3+}$, (b) $\mathrm{Ho}^{3+}$, (c) $\mathrm{Eu}^{3+}$ and (d) $\mathrm{Tm}^{3+}$ codoped Y-based microcrystals $\left(\lambda_{\text {exc }}=980 \mathrm{~nm}\right)$.

Fig. 9. Integrated intensity of upconversion fluorescence emission band of (a) ${ }^{4} \mathrm{~S}_{3 / 2} \rightarrow{ }^{4} \mathrm{I}_{15 / 2}$ and (b) ${ }^{4} \mathrm{~F}_{9 / 2} \rightarrow 4 \mathrm{I}_{15 / 2}$ vs pump power for sample Er0-4 (scattered point: measured data, solid line: linear fitting).

Fig. 10. Normalized upconversion fluorescence decay profiles of sample Er0-4 for the transitions of (a) ${ }^{4} \mathrm{~S}_{3 / 2} \rightarrow{ }^{4} \mathrm{I}_{15 / 2}$ (monitored wavelength: $538.34 \mathrm{~nm}$ ) and (b) ${ }^{4} \mathrm{~F}_{9 / 2} \rightarrow 4 \mathrm{I}_{15 / 2}$ (monitored wavelength: $653.11 \mathrm{~nm}$ ).

Fig. 11. SEM pictures of sample (a) Er5, (b) Er6, (c) Er7, (d) Er8 and (e) Er9 (scaling factor: $30 \mu \mathrm{m})$.

Fig. 12. Upconversion emission spectra (normalized to ${ }^{4} \mathrm{~F}_{9 / 2} \rightarrow{ }^{4} \mathrm{I}_{15 / 2}$ ) of single Y-based microcrystal for sample Er5-9 ( $\lambda_{\text {exc }}=980 \mathrm{~nm}$, inset: luminescent photographs for single microcrystal). 


\section{Figures}

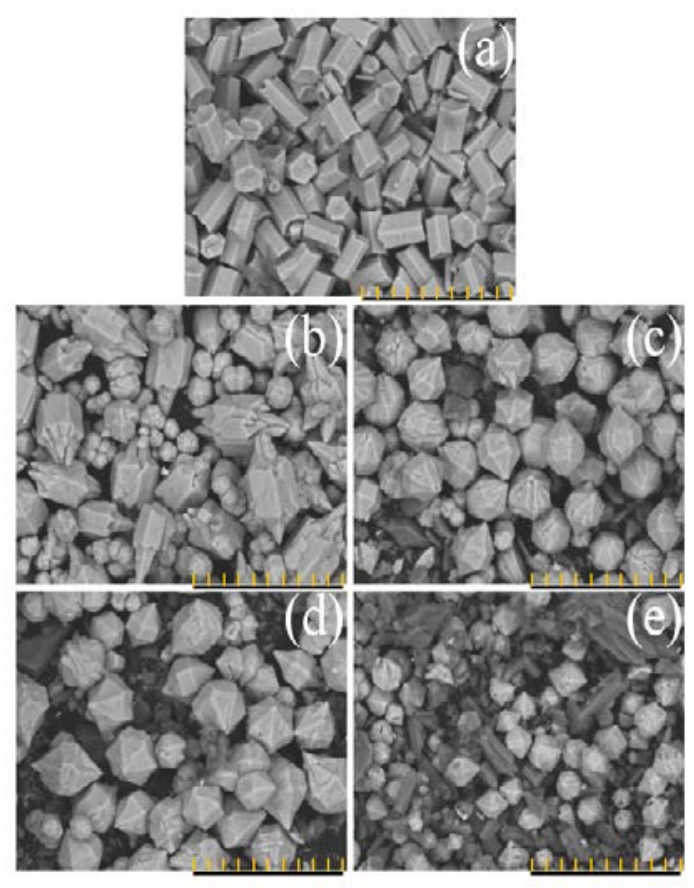

Fig. 1

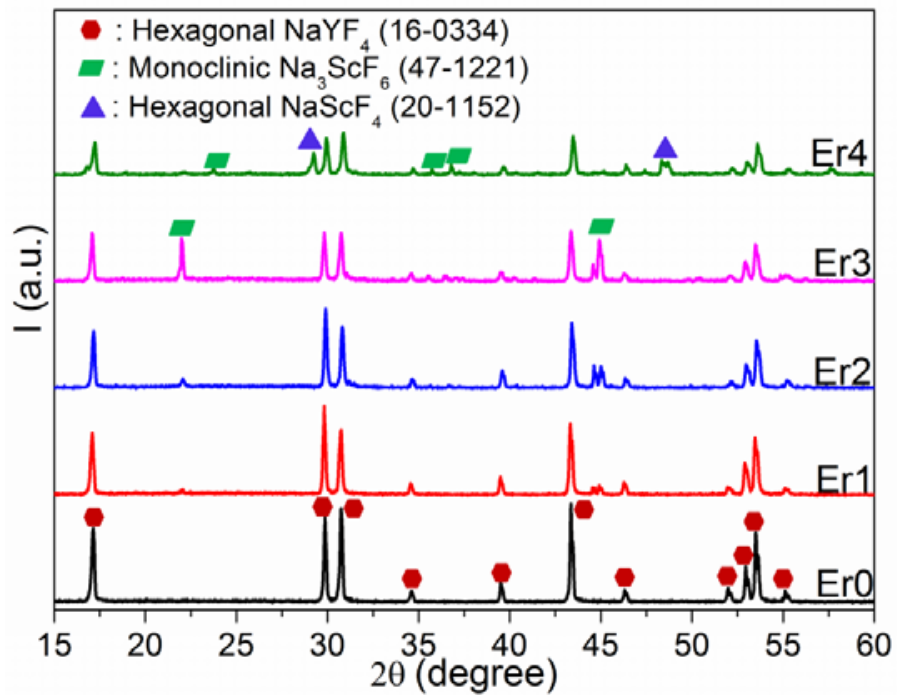

Fig. 2 

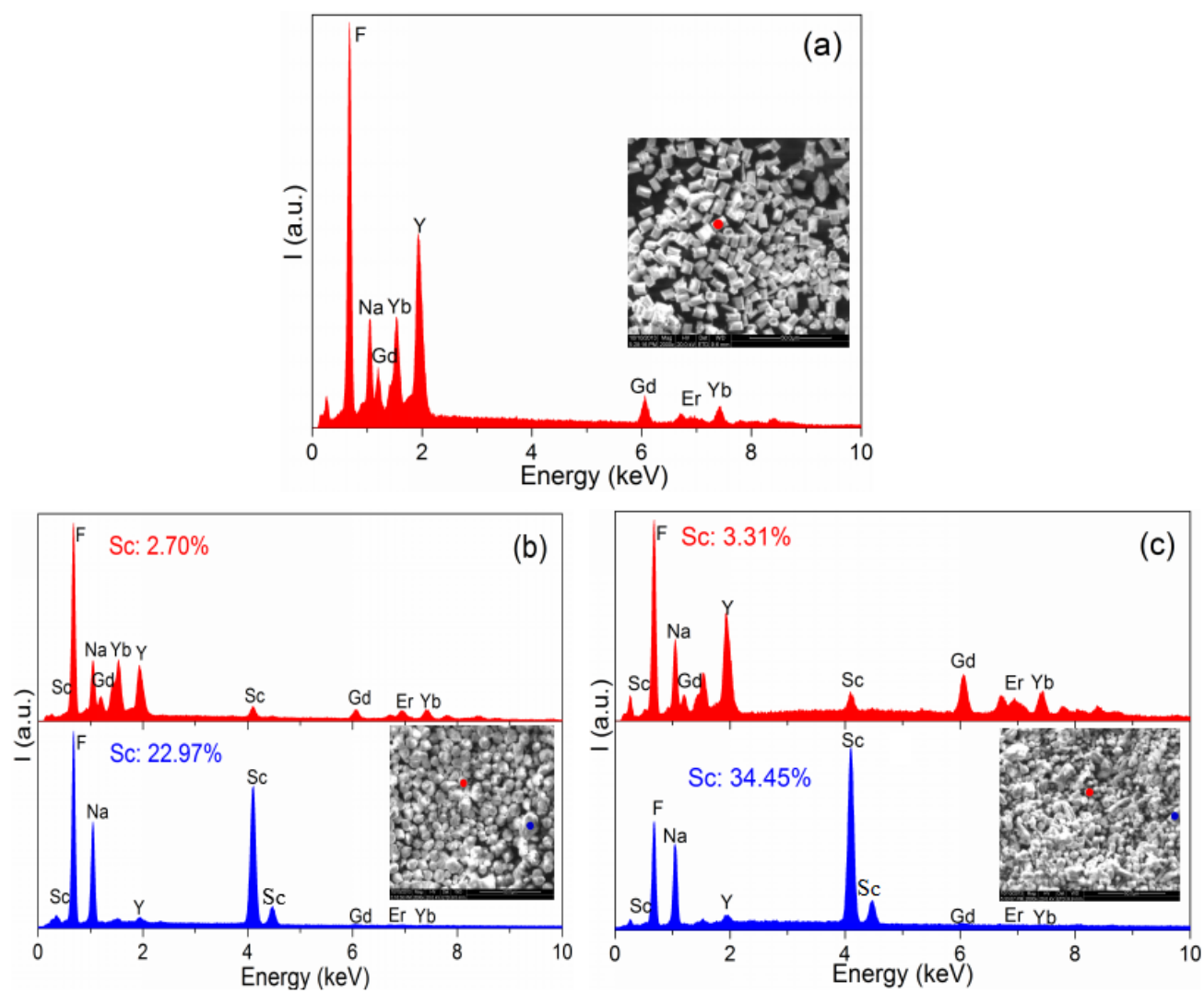

Fig. 3

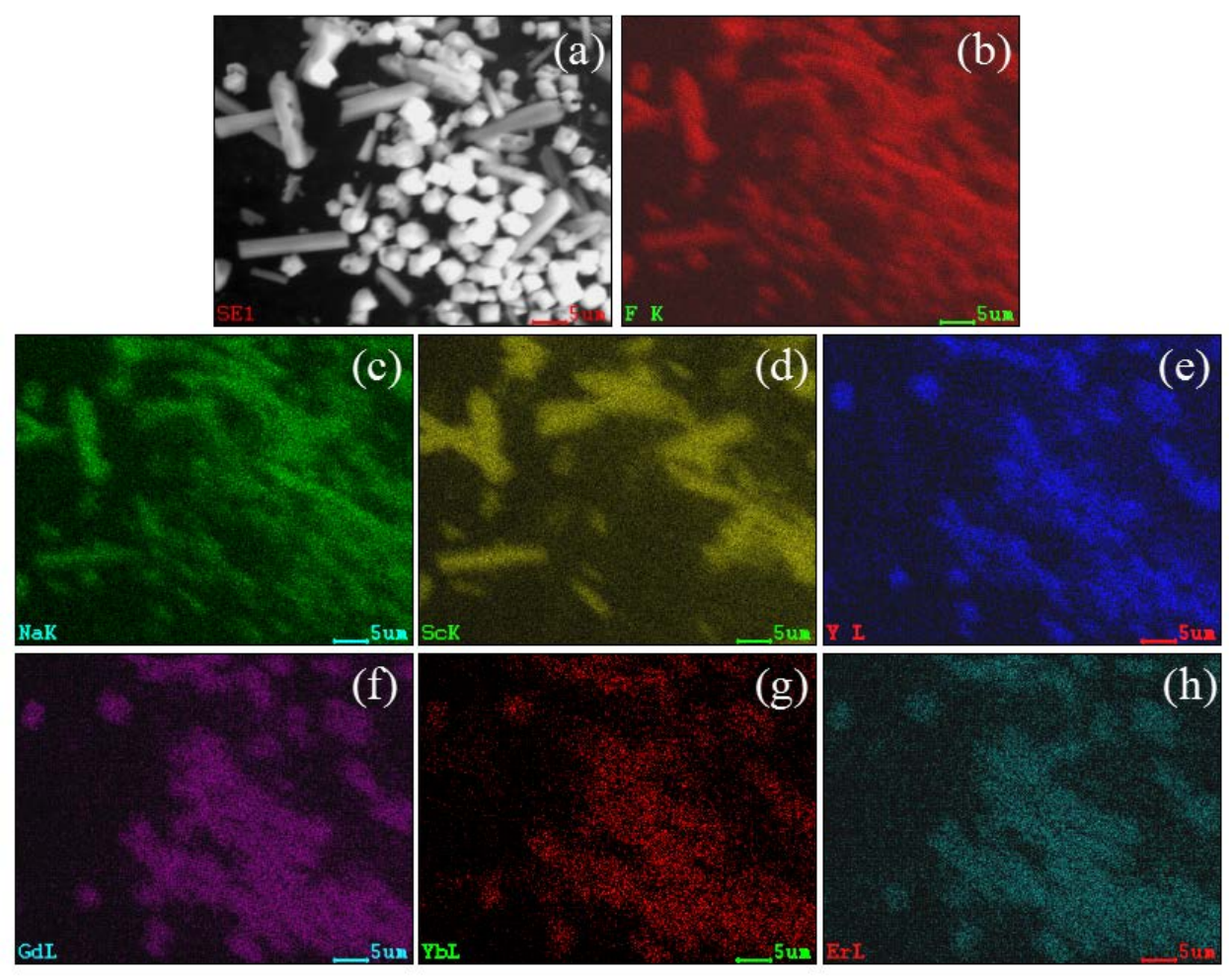

Fig. 4 


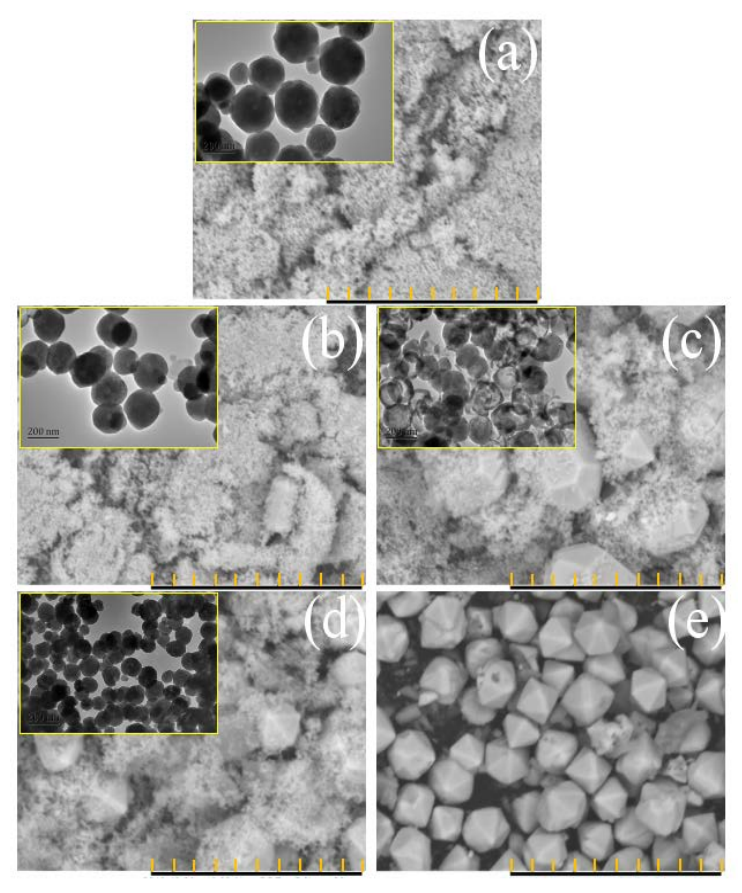

Fig. 5

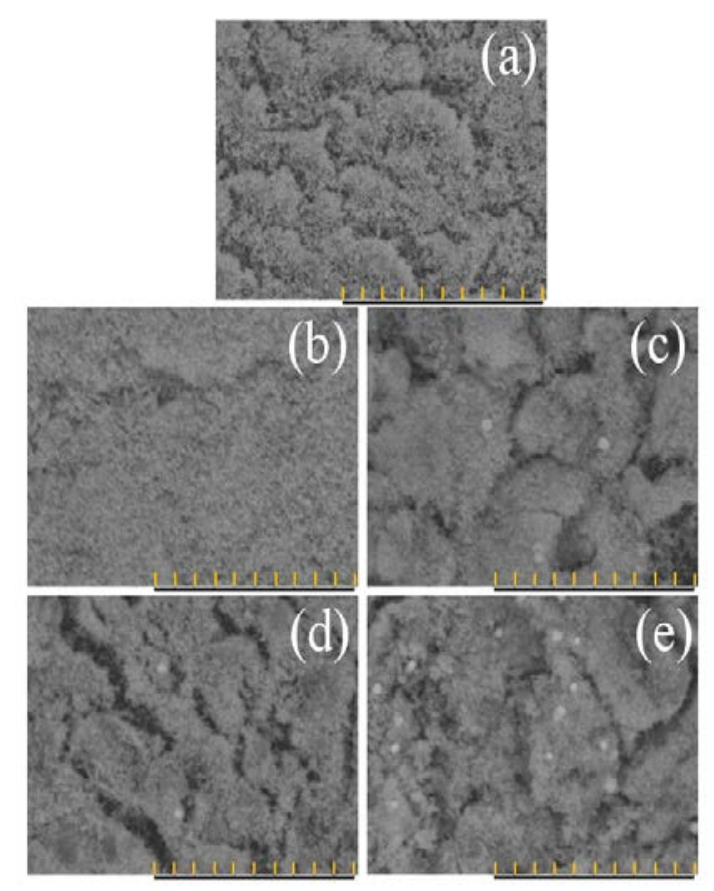

Fig. 6 

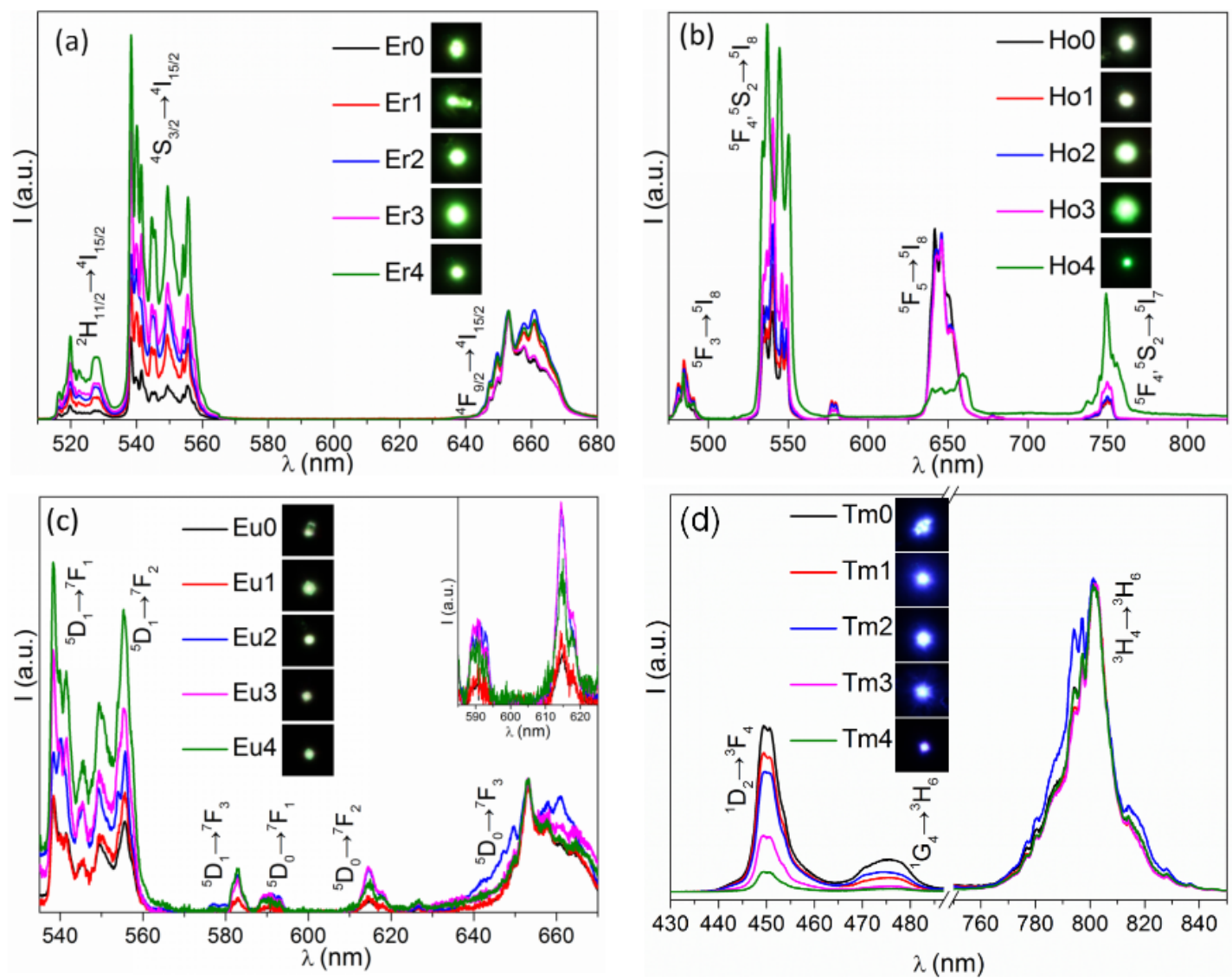

Fig. 7
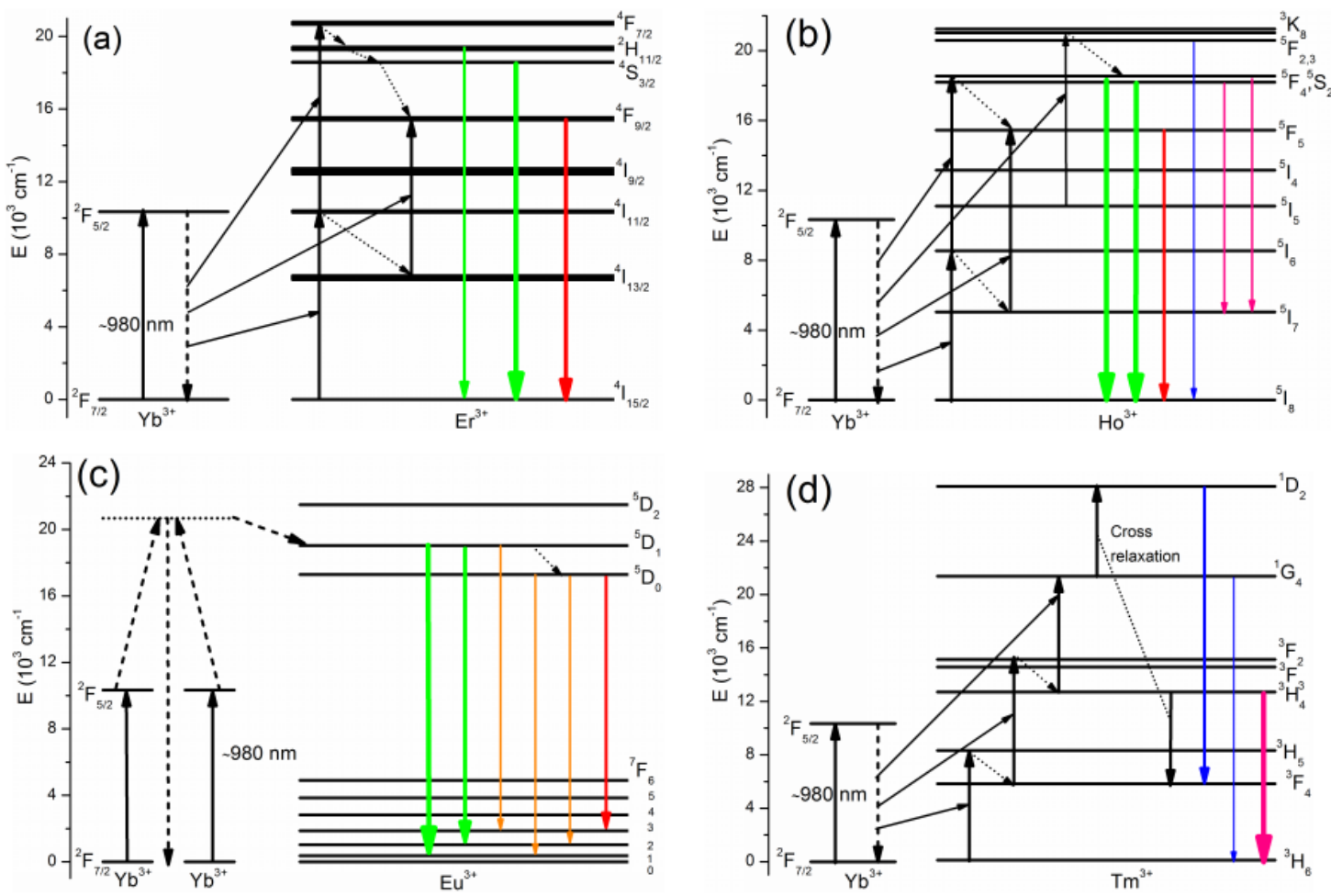

Fig. 8 

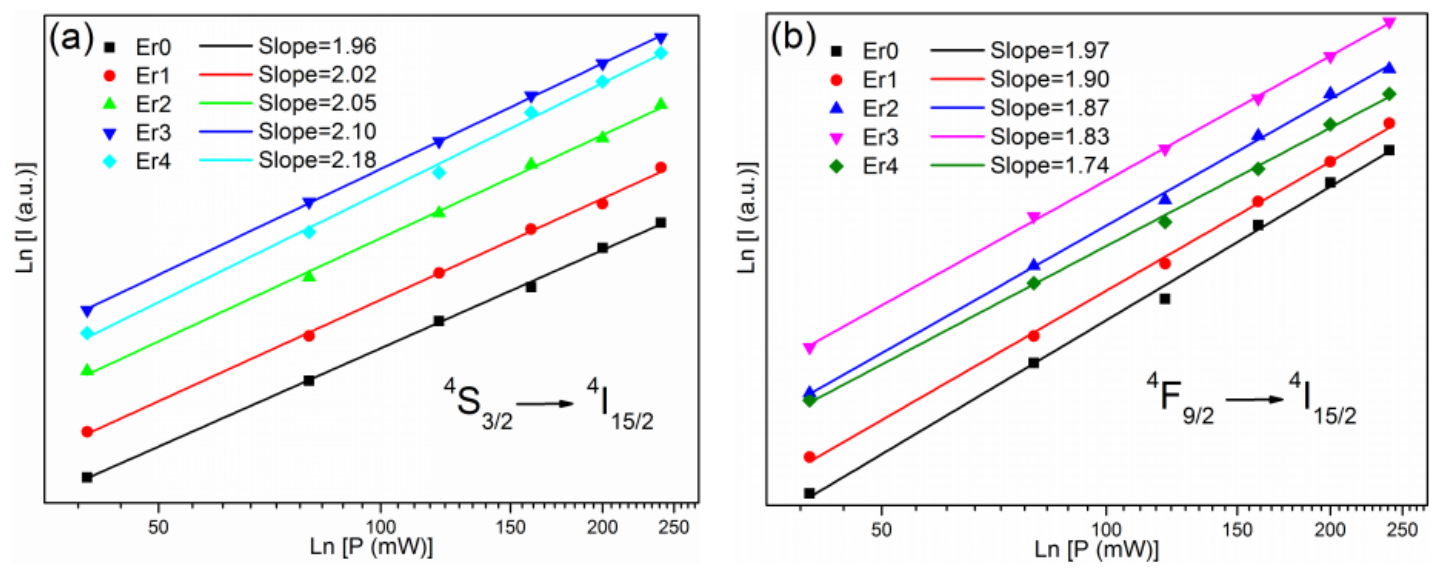

Fig. 9
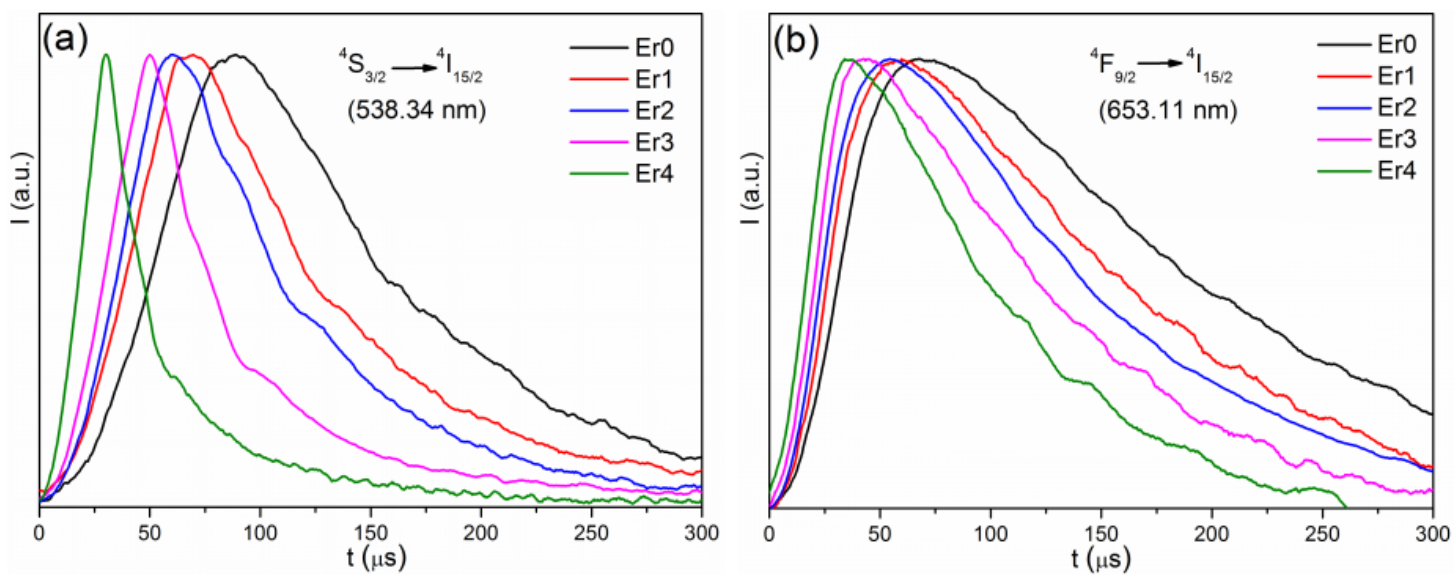

Fig. 10 


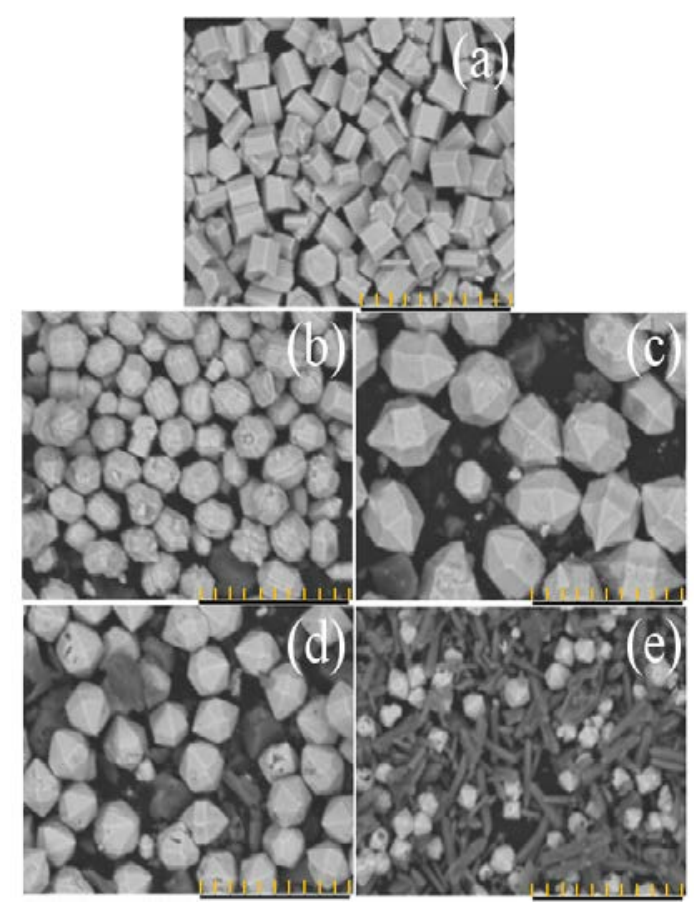

Fig. 11

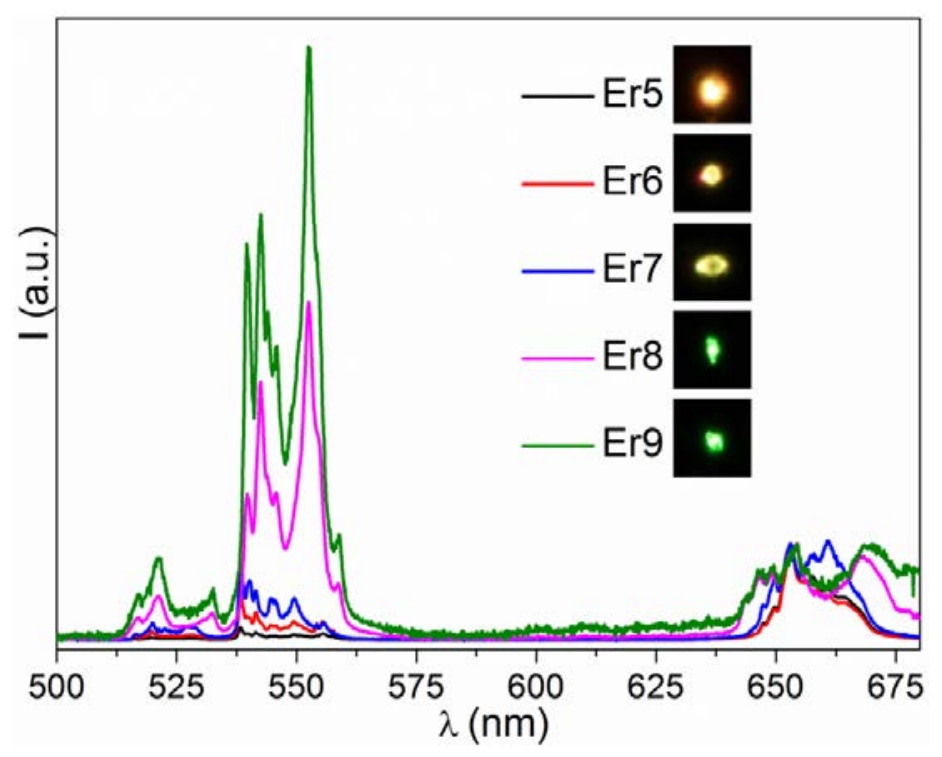

Fig. 12 